\title{
Legal Liability of Medical Toxicologists Serving as Poison Control Center Consultants: A Review of Relevant Legal Statutes and Survey of the Experience of Medical Toxicologists
}

\author{
John A. Curtis, MD, Michael I. Greenberg, MD, MPH
}

Drexel University College of Medicine, Division of Medical Toxicology, Philadelphia, PA

\begin{abstract}
Introduction: Legal liability is an increasing concern in many areas of medicine, although the extent to which this alters the practice of medicine is unclear. To date the risk for litigation against medical toxicologists serving in the role of poison control center (PCC) consultants has not been assessed.

Methods: A survey questionnaire was mailed to medical toxicologists in the United States to assess their litigation history with regard specifically to their role as PCC consultants. In addition, state laws were examined for statutes that provide protective language with regard to medical toxicologists working as PCC consults.

Results: This survey revealed that most medical toxicologists have served or currently serve as PCC consultants. Most had some degree of concern over legal liability, and several had been sued as a result of PCC consultations. Several states have specific statutes that limit the legal liability of PCCs and their employees, including medical directors and consulting medical toxicologists.

Discussion: Based on the survey results, legal action against toxicologists serving as PCC consultants appears to be an uncommon occurrence. Lawsuits are usually based upon nonfeasance and have typically been settled or dropped before trial.

Conclusions: Legal liability is a concern for PCC consultants. However, legal action against consultants appears to be rare, and respondents to the survey indicated that it did not affect their advice or willingness to serve as PC consultants. A limited number of states have enacted laws that provide protection for medical toxicologists serving as PCC consultants.
\end{abstract}

\section{INTRODUCTION}

According to the Toxic Exposure Surveillance System (TESS) data for 2005, there were more than 2.4 million human exposures and more than 1,000 poisoning- and exposure-related deaths reported each year. Medical toxicologists often serve as consultants for poison control centers (PCCs). In that role, these physicians provide real-time consultative advice to poison center personnel as well as

Keywords: medical toxicology, liability, lawsuit, poison center, legal

Acknowledgment: The authors wish to thank Kristin Karr, Esquire, for her excellent research and technical assistance.

Notes: Data in this paper were presented previously in two venues: Abstract_Legal Liability of Medical Toxicologists Serving as Poison Control Center Consultants. Clin Toxicol (43)6, 2005; and poster presentation at the 2005 NAACT conference in Orlando: Legal Liability of Medical Toxicologists Serving as Poison Control Center Consultants.

There was no outside funding of any kind used for this study.

Corresponding Author: John A. Curtis, MD, Drexel University College of Medicine, Department of Emergency Medicine, Division of Medical Toxicology, 245 North 15th Street, Mail stop 1011, Philadelphia, PA 19102. Email: jac129@gmail.com 
other physicians regarding the acute care of poisoned patients in a variety of medical settings, including private physicians' offices, clinics, emergency departments (EDs) and intensive care units (ICUs). Concern over malpractice litigation is a factor affecting many areas of clinical medicine [1-3] and medical education $[4,5]$. The extent to which service as a PCC consultant exposes a medical toxicologist to legal risk is unknown, as is the degree to which concern over malpractice influences the practice of medical toxicologists as PCC consultants. This study aimed to evaluate the prevalence of litigation related to serving as a PCC consultant as well as the degree to which the perception of this risk affected the practice of medical toxicologists serving as PCC consultants.

\section{METHODS}

A mailing list of all 2004 members of the American College of Medical Toxicology (ACMT) was obtained. A survey was designed and mailed to all US and Canadian members of ACMT. Information requested included the number of years and hours per week served as a PCC consultant as well as the dates, basis, and outcome of any lawsuits resulting solely from PCC consultation.
Respondents were asked to classify any reported lawsuits as to whether they resulted from nonfeasance (not recommending an accepted treatment) or malfeasance (recommending a treatment that possibly resulted in harm). Respondents were also asked to quantify the degree to which concern over malpractice influences their practice as PCC consultants on a 4-point numerical scale, with corresponding descriptors ranging from "not at all concerned" to "greatly concerned." Replies were returned anonymously via facsimile to a secure, dedicated fax line. In addition, computer-based Lexis-Nexis searches of all 50 states were performed for both lawsuits filed against medical toxicologists and statutes affecting PCC consultants. This study was reviewed and received exempt status from the Drexel University College of Medicine Institutional Review Board.

\section{RESULTS}

A total of 152 of a possible 395 ACMT members (38.4\%) responded to the survey. Of the 152 respondents, 117 (78\%) indicated that they were active poison center consultants and 149 $(98 \%)$ had served as a PCC consultant within the past 10 years (Figure 1). Seventy (46\%) respondents served for greater than 10 years,

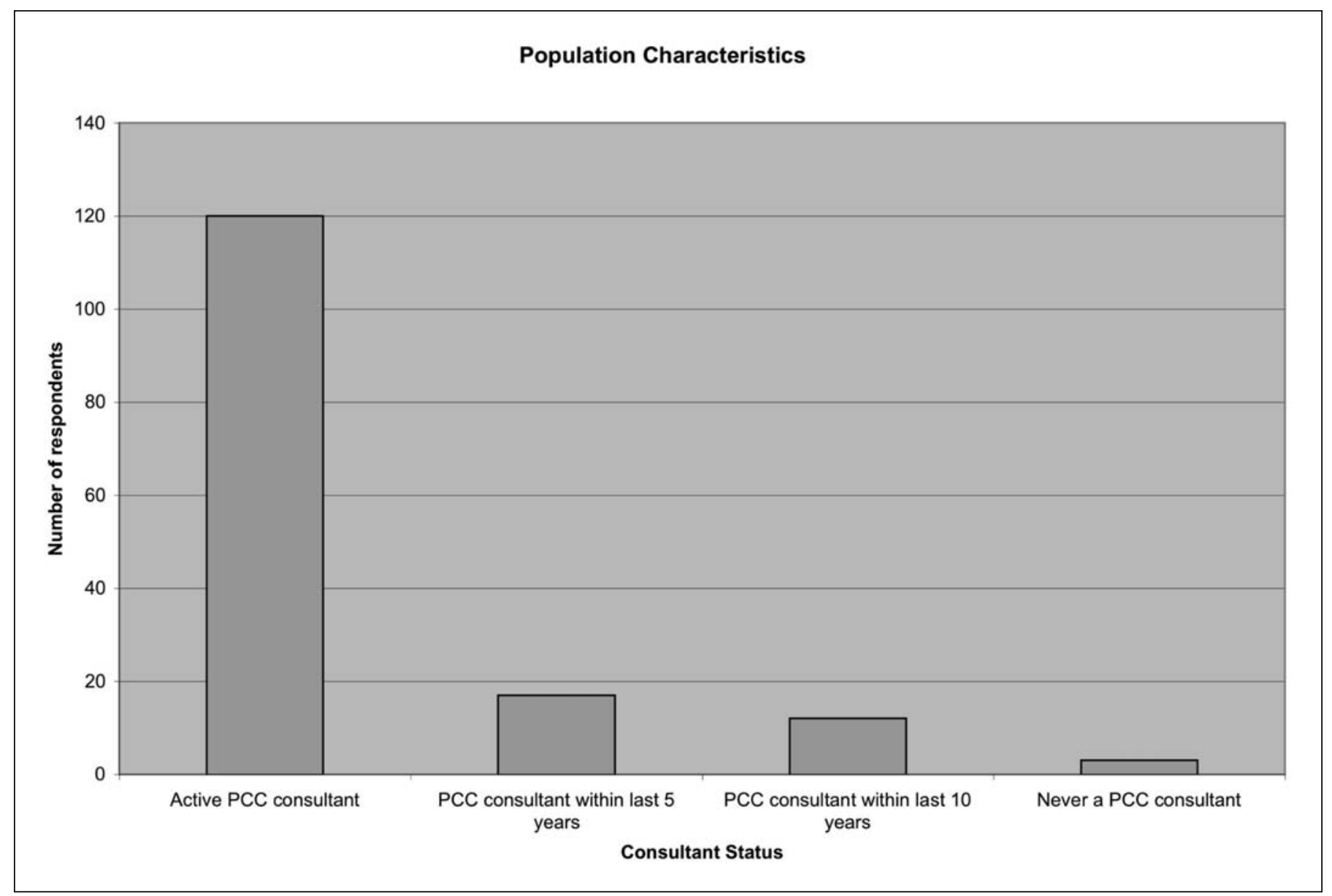

Figure 1: Reported service as Poison Control Center consultants for survey respondents. 
while only 10 served for less than 1 year. A total of 121 (79\%) consultants described at least some concern over the potential for legal liability related to activities as PCC consultants (Figure 2). Nine lawsuits were reported by 8 respondents; 7 were for nonfeasance, which included 2 cases that were dropped prior to settlement and 1 case in which the consulting toxicologist was protected from liability by state law. Two cases of alleged malfeasance were settled prior to trial. The 6 respondents who reported being named in the 7 most recent lawsuits were still active consultants, while the 2 respondents with the claims filed more than 15 years ago had served within the last 10 years.

Lexis-Nexis search revealed that 9 states have enacted laws meant to protect poison center personnel from legal liability. In addition, most states include "Good Samaritan" and/or volunteer statutes that potentially exempt volunteers providing emergency consultation through PCCs. For these statutes to be applicable, it is generally necessary that the volunteers be unpaid and their consultative services provided free of charge. It is important to note that the interpretation of these statutes varies from state to state. It is also important to note that no statute exempts physicians from grossly negligent conduct under any circumstances.

\section{STATE STATUTES THAT LIMIT LIABILITY OF POISON CONTROL CENTER CONSULTANTS}

Statues that limit legal liability essentially set forth circumstances in which, by law, PCC consultants cannot be found liable for certain acts and omissions. This legal protection means that there would be no basis for any suit against a consultant if the requirements set forth by the statutes have been met. The following states and statues were identified:

\section{Arkansas}

Since 1991, Arkansas has limited the liability of the Arkansas Poison and Drug Information Center, its personnel, and its designees from any personal liability or legal jeopardy for "information proffered in good faith, professional judgments and responses provided for the system, or any good faith professional effort to effectuate the purposes of this subchapter." Relevant statute: A.C.A. § 20-13-704 (2004)

\section{California}

Since 1988, a designated regional PCC that "provides information and advice for no charge on the management of exposures

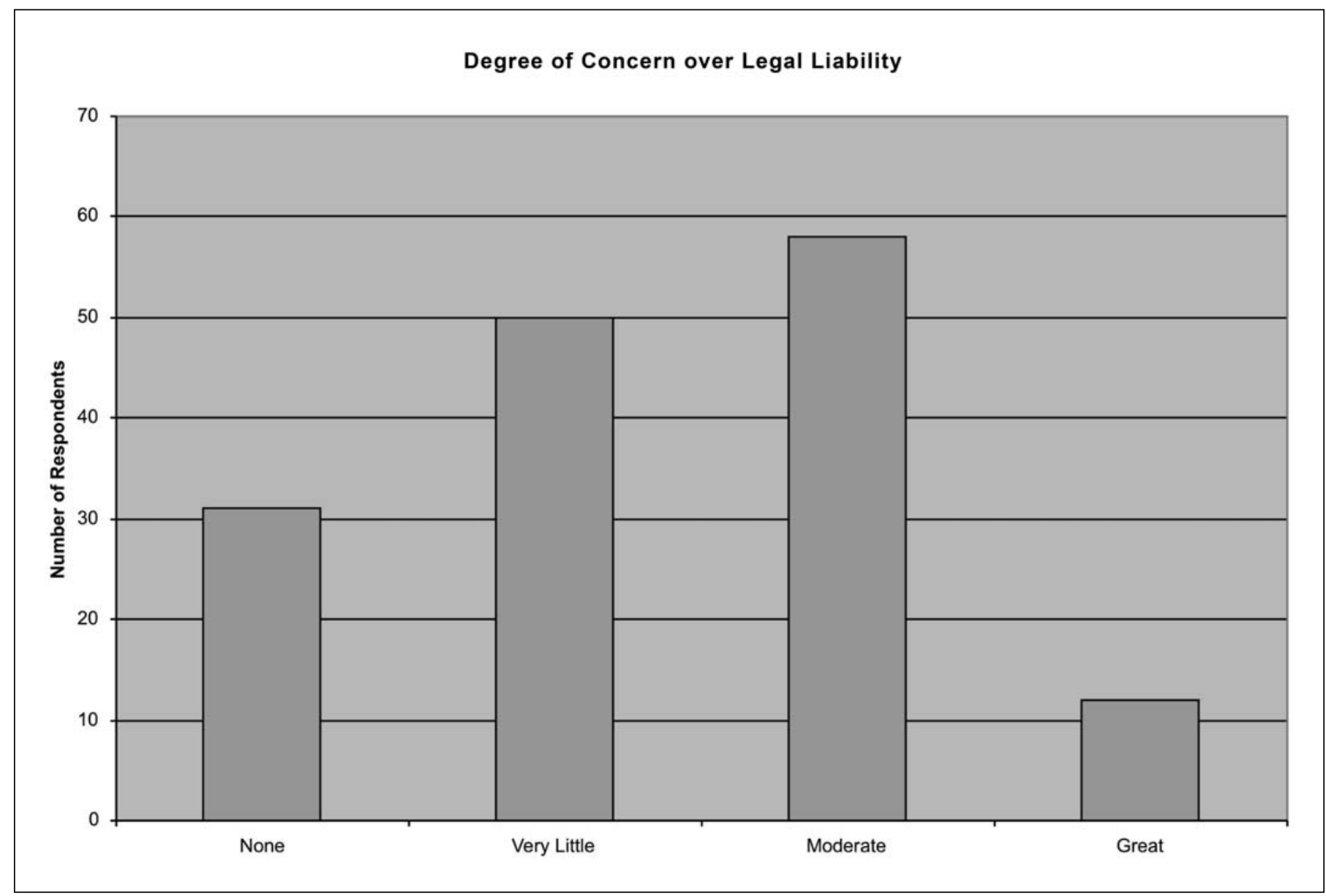

Figure 2: Degree to which survey respondents reported concern over legal liability arising from serving as PCC consultant. 
to poisonous or toxic substances, shall be immune from liability in civil damages" as long as that information is in accordance with PCC protocols. Liability only applies for grossly negligent advice, or errors or omissions not performed in good faith. Relevant statute: Cal Health \& Saf Code § 1799.105 (2005)

\section{Florida}

In Florida, PCC consultants are considered agents of the State of Florida, Department of Health and are not held personally liable as a result of any act, event, or omission of action in the scope of her or his employment or function, unless such officer, employee, or agent acted in bad faith or with malicious purpose or in a manner exhibiting wanton and willful disregard of human rights, safety, or property. Relevant statute: Fla. Stat. § 768.28 (2004)

\section{Louisiana}

Since 1989 in Louisiana, nonprofit certified PCCs, their employees or volunteers are not liable for civil damages for any information provided in good faith, except in the case of gross negligence or willful or wanton misconduct. Relevant statute: La. R.S. § 9:2797.1. (2004)

\section{Ohio}

Since 1989, Ohio has held PCCs to be not liable in damages in a tort action for harm that arises from advice or assistance, once again excepting willful or wanton misconduct or intentionally tortious conduct. Relevant statute: ORC Ann. § 3701.20 (2005)

\section{Tennessee}

Since 1991, "No act done or omitted in good faith while performing duties as a medical director, consultant, or specialist in poison information of a regional poison control center shall impose any liability on the poison control center, its officers, volunteers, medical directors, consultants, specialists in poison information, other employees or a person, organization or institution that advises a regional poison control center, unless the advice or assistance is given in a manner that constitutes willful or wanton misconduct." Relevant statute: Tenn. Code Ann. § 68-141-107 (2004)

\section{Washington}

Since 1987, Washington has enacted laws that protect PCC medical directors, poison information specialists and other employees from any liability for any act or omission performed in good faith and within their area of responsibility and expertise, excepting gross negligence or willful or wanton conduct. Relevant statute: Rev. Code Wash. (ARCW) § 18.76.070 (2004)

\section{STATE STATUTES THAT INDEMNIFY POISON CONTROL CENTER CONSULTANTS}

In contrast to states that limit legal liability, others have chosen to indemnify PCC consultants. In such states, a legal complaint could be filed, but the state is obligated to some degree to com- pensate the indemnified consultant for any damages for which he or she is found to be responsible.

\section{Illinois}

In Illinois, a designated PCC that receives state funding, and individuals who render professional advice and consultation to it, are entitled to representation by the State Attorney General (SAG) (unless this represents a conflict of interest or the SAG finds that the act was intentional, willful or wanton misconduct). Furthermore, the State will cover the costs of any judgment against the PCC consultant, including litigation expenses and attorney's fees (to the extent approved by the Attorney General as reasonable). Relevant statutes: § 5 ILCS 350/1, § 5 ILCS 350/2

\section{Texas}

In Texas, the state indemnifies a PCC and an employee of a PCC under Chapter 104, Civil Practice and Remedies Code. Relevant Statute: Tex. Health \& Safety Code $§ 777.007$ (2004)

\section{DISCUSSION}

Based on the survey results, legal action against toxicologists serving as PCC consultants appears to be an uncommon occurrence. Due to anonymity of the respondents, it was not possible to analyze responses by geographical region. Lawsuits are usually based on nonfeasance, and have typically settled or dropped before trial. While concern over liability was common for the survey respondents, it did not seem to be effected by a history of legal action. There were no cases in which a PCC consultant appeared to retire or resign from that position as a result of malpractice litigation. Knowledge of the national prevalence of such litigation, as well as awareness of the local practice environment, is necessary to effectively assess the degree of legal risk assumed by medical toxicologists serving as PCC consultants. Risk may vary from state to state as well, based on state-specific protective legislation.

There were two main strategies identified by which states specifically attempted to protect poison center consultants from legal liability in cases arising from service as PCC consultants.

The first such strategy identified involves the limitation of potential liability. Arkansas, California, Florida, Louisiana, Ohio, Tennessee, and Washington all adopted statutes between 1987 and 2004 that specifically limit the personal liability of PCC personnel. It should be noted that this usually assumes that consultations conformed to existing PCC protocols and consultative advice was given in good faith. These statutes do not provide protection in the event of recommendations that might be grossly negligent or those given with malicious intent.

Other states specifically indemnify individual consultants as operatives of the state. Illinois and Texas will indemnify PCC employees and others who volunteer professional consultation on behalf of a state-funded agency. Illinois also provides for defense against legal action by the SAG in cases where the services provided by the consultant were within the scope of their employment and were not deemed to be willful or wanton misconduct. 
A list of state statutes relevant to PCC operations is maintained by the National Conference of State Legislatures at www.ncsl.org/programs/health/poilaws.htm. It is recommended that PCC consultants familiarize themselves with the laws affecting their region of practice.

\section{LIMITATIONS}

Limitations of the current study include the relatively low response rate of $38.5 \%$, as well as the fact that ACMT members do not represent all medical toxicologists serving as PCC consultants. This could have resulted in some PCC-based litigation cases being missed. It is also possible that medical toxicologists who had been the subject of legal action would be more or less likely to respond to the survey, thereby biasing the results. In addition, it is possible that some states may have enacted or changed legislation since the completion of this study.

\section{CONCLUSIONS}

Legal liability is a concern for PCC consultants. However, legal action against consultants appears to be rare, and respondents to the survey indicated that it did not affect their advice or willingness to serve as PCC consultants. Several states offer specific limitations on liability or indemnification. PCC consultants should be aware of the specific laws affecting practice in their states.

The authors both serve as consultants to the regional poison control center in Philadelphia, PA.

\section{REFERENCES}

1. Campbell WB, France F, Goodwin HM. Medicolegal claims in vascular surgery. Ann R Coll Surg Engl 2002;84(3):181-184.

2. Wick MR, Foucar E, Allen PW et al. Medicolegal liability in pathology: an international perspective. Semin Diagn Pathol 2007;24(2):65-76.

3. Gorney M. Preventing litigation in breast augmentation. Clin Plast Surg 2001;28(3):607-615.

4. Brilla R, Evers S, Deutschländer A et al. Are neurology residents in the United States being taught defensive medicine? Clin Neurol Neurosurg 2006;108(4):374-377.

5. Houry D, Shockley LW. Evaluation of a residency program's experience with a one-week emergency medicine resident rotation at a medical liability insurance company. Acad Emerg Med 2001;8(7):765-767. 